AperTO - Archivio Istituzionale Open Access dell'Università di Torino

\title{
Curious about the price? Consumers' behavior in price reveal auctions
}

\section{This is a pre print version of the following article:}

Original Citation:

\section{Availability:}

This version is available http://hdl.handle.net/2318/1777635

since 2021-03-05T10:49:36Z

Published version:

DOI:10.1080/13504851.2021.1893263

Terms of use:

Open Access

Anyone can freely access the full text of works made available as "Open Access". Works made available under a Creative Commons license can be used according to the terms and conditions of said license. Use of all other works requires consent of the right holder (author or publisher) if not exempted from copyright protection by the applicable law. 


\title{
Curious about the price?
}

\section{Consumers' behavior in price reveal auctions}

\author{
Andrea Gallice* Giuseppe Sorrenti ${ }^{\dagger}$
}

\begin{abstract}
We exploit some specific features of a peculiar online selling mechanism, the so-called price reveal auctions, to empirically investigate how consumers' behavior changes in response to an item's 'social attributes'. We document a significant effect of the item's brand and intended use (outdoor vs. indoor) in influencing consumers' degree of impatience and willingness to pay. We show that, although both variables have some explanatory power when considered in isolation, it is their interaction that really matters.
\end{abstract}

JEL Codes: D44, D12.

Keywords: price reveal auction; willingness to pay; impatience; social attributes; positional goods.

\footnotetext{
*University of Torino (ESOMAS Department) and Collegio Carlo Alberto. Corresponding Author: Piazza Arbarello 8, 10122, Torino, Italy.Email: andrea.gallice@unito.it.

†University of Amsterdam (School of Economics).Email: g.sorrenti@uva.nl.
} 


\section{Introduction}

We study consumers' behavior in price reveal auctions (PRAs). A PRA works as follows: the seller announces that an auction for a certain item (say, the latest fashionable smartphone) is open but keeps the starting price hidden. At any point in time, participants can privately observe the current price. However, to observe the price they must pay the seller a fee $c>0$. An agent who observes the price must then decide whether or not to buy the item. If the agent buys the item, the auction closes. If the agent does not buy the item, the price goes down by a predetermined amount $\Delta<c$ and the auction continues 1

A PRA thus differs from a standard descending auction (see Krishna, 2002) in two fundamental aspects: first, the current price of the item is not publicly observable; and second, the price does not fall exogenously as a function of time, but rather endogenously in response to participants' behavior. These features make the mechanism particularly apt to study the determinants of agents' anxiety to buy. Contrary to a standard descending auction, the fact that agents must pay a fee to observe the price explicitly reveals their interest in the good. Contrary to a standard ascending auction where agents can overbid each other, the fact that bidders do not observe others' behavior does not mitigate the risk of being preempted by a rival.

We assembled a unique dataset that includes detailed information about 134 PRAs. Overall, these auctions attracted 53,996 price observations. We document significant differences in agents' attitudes towards specific types of products and/or brands. In particular, we exploit substantial heterogeneity in the duration of the auctions and in the size of the final discount (i.e., the difference between the retail price

\footnotetext{
${ }^{1}$ PRAs belong to the family of so-called "pay-per-bid auctions", which also include penny auctions (Augenblick, 2016; Hinnosaar, 2016) and lowest unique bid auctions (Gallice, 2009; Eichberger and Vinogradov, 2015). Gallice (2016) investigates PRAs from a theoretical point of view. The popularity of pay-per-bid auctions peaked around 2011 and declined thereafter.
} 
and the price the winner pays) to make several inferences about consumers' eagerness to obtain certain goods. This heterogeneity stems from how buyers deal with the key trade-off that characterizes the PRA. On the one hand, the longer an agent waits, the more likely the price will fall by a substantial amount (because other consumers will observe the price). On the other hand, the longer an agent waits, the more likely the auction will close (because someone else buys the item). Clearly, the way participants solve this trade-off may vary across different auctions on the basis of the characteristics of the item on sale.

Our empirical analysis confirms these intuitions. We find that PRAs that offer items that increase the owner's status (Rege, 2008), self-image (Johansson-Stenman and Martinsson, 2006), or elicit envy (Van de Ven et al., 2011) generate a lower number of price observations, sell the item at a lower discount, and produce lower profits. We also find that the real driver of these effects is not the brand effect per se, but rather the interaction between the brand effect and the intended use of the item: when the positional good is an outdoor product, external visibility increases and so does the saliency of the item's social attributes.

We also study the determinants of the mechanism's profitability and of the level of agents' participation. We find that the PRA format generates an average profit margin of $36 \%$. Profits tend to be larger in auctions with more valuable goods. Expensive items attract a larger number of price observations which, through the accrual of the associated bidding fees, are the main source of revenue for the seller. However, and perhaps surprisingly, we find that the size of the bidding fee does not have a significant impact on profits. We rationalize this result by showing how an increase in the bidding fee triggers two opposite effects that basically cancel out. First, a large fee raises the marginal revenue generated by every single price observation. Second, a large fee reduces the level of participation in a non-random way. In particular, 
auctions with large fees only appeal to those agents who are particularly eager to buy the item (i.e., those with a high willingness to pay). These agents are thus more likely to buy the item (and thus end the auction), no matter the price they observe. As a result, the auction attracts a lower number of price observations.

\section{The Analysis}

\subsection{Data and Descriptive Statistics}

We assembled a dataset containing publicly available information about all 134 PRAs that took place on the website Bidster.com, the market leader in the sector. The website introduced the PRA format in December 2009 and ceased its activities in April 2011. Auctioned items include smartphones, tablets, TV sets, computers, MP3 readers, watches, and accessories.

Table 1: Descriptive statistics

\begin{tabular}{lccccc}
\hline \hline Variables & Mean & St.Dev. & Median & Min. & Max. \\
\hline Retail Price & 442.77 & 374.30 & 320 & 25 & 1,700 \\
Final Price & 302.23 & 278.27 & 210.50 & 6 & 1,278 \\
Bidding Fee & 1.07 & 1.08 & 0.50 & 0.50 & 10 \\
Price Decrease & 0.53 & 0.54 & 0.25 & 0.25 & 5 \\
Discount (\%) & 0.36 & 0.16 & 0.34 & 0.07 & 0.97 \\
Duration (hours) & 1,211 & 1,118 & 862 & 17 & 7,388 \\
Number of price obs. & 402.95 & 436.97 & 296 & 4 & 3,595 \\
Profits & 140.53 & 132.67 & 111.37 & 3.50 & 983 \\
\hline Apple & 0.25 & - & - & 0 & 1 \\
Outdoor & 0.26 & - & - & 0 & 1 \\
Apple \& Outdoor & 0.19 & - & - & 0 & 1 \\
\hline Observations & & \multicolumn{7}{c}{134} \\
\hline \hline
\end{tabular}

All monetary values are expressed in $€$. 
Table 1 reports the descriptive statistics of the data. On average, participants observed the price 403 times, with a significant variability in terms of standard deviation (437) and min-max range $(3,591)$. This variability is due to the substantial heterogeneity in the economic value of the auctioned items: the average retail price is $€ 443$, with a minimum of $€ 25$ and a maximum of $€ 1,700$. The average bidding fee $c$ is approximately $€ 1$, whereas the price decrease $\Delta$ is always set as $\Delta=\frac{1}{2} c$. The mechanism's profitability is remarkable. The average profit amounts to $€ 140$, which is $36.5 \%$ of the average retail price. The bottom part of the Table shows descriptive statistics about the social attributes of the items. To assess whether possible differences in participants' behavior are related to the specific characteristics of the item on sale, we introduced a classification based on a dual criterion. The aim is to try to disentangle the influence that the social attributes of the item, such as the brand and the degree of public visibility, may have on the participants' willingness to pay. We therefore introduced two indicator variables. The first one (Apple) takes value one if the item is an Apple-branded product. It is widely recognized that Apple's success is largely based not only on the intrinsic quality of its products, but also on the importance of the brand and the social status it confers. The second indicator variable (Outdoor) defines outdoor high-tech products such as smartphones, tablets and MP3 readers. About $25 \%$ of the items are Apple-branded and $26 \%$ are outdoor products. The intersection of these two sets represents approximately $19 \%$ of all the auctioned items.

\subsection{The Econometric Model}

The econometric analysis aims at investigating the main determinants of the profits $(\pi)$ and the total number of price observations $(\eta)$. We thus estimate the following 
baseline equations:

$$
\begin{gathered}
\pi=\beta_{0}+\beta_{1} p_{\text {ret }}+\beta_{2} c+\beta_{3} \text { Apple }+\beta_{4} \text { Outdoor }+\beta_{5} \text { Apple } * \text { Outdoor }+\varepsilon \\
\eta=\gamma_{0}+\gamma_{1} p_{\text {ret }}+\gamma_{2} c+\gamma_{3} \text { Apple }+\gamma_{4} \text { Outdoor }+\gamma_{5} \text { Apple } * \text { Outdoor }+u
\end{gathered}
$$

where $p_{\text {ret }}$ represents the retail price, $c$ is the bidding fee, Apple indicates Applebranded products and Outdoor indicates products that are used in outdoor daily life. The interaction term Apple *Outdoor allows us to capture the combined effect of being an Apple-branded product aimed at an outdoor use. Ordinary least squares estimates of equations (1) and (2) are reported in Table 2. The upper panel refers to auctioneer's profit, while the lower one focuses on the number of price observations.

The importance of the retail price in determining an auction's profitability stands out. The coefficient is positive, significant, and remarkably constant across all model specifications. A $1 \%$ increase in an item's retail price translates to an increase in the profit of almost $€ 1$. The amount of the bidding fee is positively related with profits, although the coefficient is small in magnitude and not statistically significant. This negligible effect is caused by the combination of two opposing effects. On the one hand, a larger $c$ positively influences profits, as it increases the marginal revenue generated by every price observation. On the other hand, a larger bidding fee discourages a participant from observing the price, unless the agent is highly interested in the item. As a consequence, players that observe the price are likely to have a higher willingness to pay, and thus are ultimately more likely to buy the item. Thus, the total number of price observations - the main source of profits for the seller - gets depressed (see the lower panel for evidence on the negative effect of $c$ on $\eta$ ).

When considered in isolation, the variables Apple, Outdoor, and Apple *Outdoor all explain a significant decrease in profits. The magnitude of these coefficients pro- 
Table 2: The determinants of auctioneer's profit and the number of price observations

\begin{tabular}{|c|c|c|c|c|c|c|}
\hline \multicolumn{7}{|c|}{ Dependent variable: Profits } \\
\hline & (1) & (2) & (3) & (4) & $(5)$ & (6) \\
\hline $\log ($ Retail Price $)$ & $\begin{array}{c}94.41 * * * \\
(14.74)\end{array}$ & $\begin{array}{c}93.96 * * * \\
(14.65)\end{array}$ & $\begin{array}{c}95.78 * * * \\
(15.09)\end{array}$ & $\begin{array}{c}98.69 * * * \\
(16.08)\end{array}$ & $\begin{array}{c}97.89 * * * \\
(15.39)\end{array}$ & $\begin{array}{c}98.73 * * * \\
(16.23)\end{array}$ \\
\hline $\log$ (Bidding Fee) & & $\begin{array}{c}7.44 \\
(13.69)\end{array}$ & $\begin{array}{c}2.20 \\
(14.10)\end{array}$ & $\begin{array}{c}1.74 \\
(13.93)\end{array}$ & $\begin{array}{c}1.98 \\
(13.78)\end{array}$ & $\begin{array}{c}2.64 \\
(14.57)\end{array}$ \\
\hline Apple & & & $\begin{array}{c}-30.70^{*} \\
(18.51)\end{array}$ & & & $\begin{array}{c}17.48 \\
(13.57)\end{array}$ \\
\hline Outdoor & & & & $\begin{array}{l}-40.29 * \\
(21.37)\end{array}$ & & $\begin{array}{l}-12.53 \\
(24.60)\end{array}$ \\
\hline Apple \& Outdoor & & & & & $\begin{array}{c}-47.75^{* *} \\
(21.24)\end{array}$ & $\begin{array}{c}-52.60 * * \\
(24.44)\end{array}$ \\
\hline $\mathrm{N}$ & 134 & 134 & 134 & 134 & 134 & 134 \\
\hline$R^{2}$ & 0.45 & 0.46 & 0.47 & 0.47 & 0.47 & 0.48 \\
\hline \multicolumn{7}{|c|}{ Dependent variable: Number of price observations } \\
\hline $\log ($ Retail Price $)$ & $\begin{array}{c}257.88 * * * \\
(49.38)\end{array}$ & $\begin{array}{c}274.80 * * * \\
(46.63)\end{array}$ & $\begin{array}{c}283.26^{* * * *} \\
(48.09)\end{array}$ & $\begin{array}{c}296.48 * * * \\
(51.32)\end{array}$ & $\begin{array}{c}291.62 * * * \\
(49.02)\end{array}$ & $\begin{array}{c}296.30 * * * \\
(51.47)\end{array}$ \\
\hline $\log$ (Bidding Fee) & & $\begin{array}{c}-278.36 \text { *** } \\
(34.06)\end{array}$ & $\begin{array}{c}-302.78^{* * *} \\
(40.21)\end{array}$ & $\begin{array}{c}-304.49 * * * \\
(39.94)\end{array}$ & $\begin{array}{c}-301.73 * * * \\
(37.87)\end{array}$ & $\begin{array}{c}-303.35^{* * *} \\
(42.75)\end{array}$ \\
\hline Apple & & & $\begin{array}{c}-143.06^{* *} \\
(65.91)\end{array}$ & & & $\begin{array}{c}32.32 \\
(53.86)\end{array}$ \\
\hline Outdoor & & & & $\begin{array}{c}-184.82 * * \\
(73.18)\end{array}$ & & $\begin{array}{l}-93.63 \\
(84.75)\end{array}$ \\
\hline Apple \& Outdoor & & & & & $\begin{array}{c}-204.32 * * * \\
(71.50)\end{array}$ & $\begin{array}{c}-150.95^{*} \\
(85.03)\end{array}$ \\
\hline $\mathrm{N}$ & 134 & 134 & 134 & 134 & 134 & 134 \\
\hline$R^{2}$ & 0.31 & 0.51 & 0.53 & 0.54 & 0.54 & 0.54 \\
\hline
\end{tabular}

Robust standard errors are reported in brackets. *,**,*** denotes statistical significance at $10 \%, 5 \%$ and $1 \%$ level respectively.

gressively increases (respectively, $-31,-40$, and -48). Moreover, the coefficient for the interaction term remains the only statistically significant one in the complete model. Indeed, the estimates of the complete model (see column 6) stress the role played by the positional nature of certain goods. Notice in fact that the coefficient for Apple products shifts to a positive (albeit not significant) value when the variable that captures the level of external visibility is included. This indicates that the level of 
consumer impatience, and thus its consequences on profits, is not strongly influenced by the brand effect per se, but rather by the combination of brand and visibility.

The determinants of the number of price observations are analyzed in the lower panel of Table 2. Monetary variables are significant predictors of the number of price observations. The effect of the retail price is positive and statistically significant. A $1 \%$ increase in the retail price translates to an increase in the number of price observations between 2.6 and 3 . The effect of the bidding fee is similar in magnitude but opposite in sign because an increase in $c$ lowers the number of price observations. Columns (3) to (6) display the effects of the brand and the level of external visibility. The Apple coefficient is extremely high both in terms of absolute value and in statistical significance: on average, an Apple-branded product generates 143 price observations fewer than an item of a different brand. Even more pronounced is the Outdoor coefficient: in this case, a product that is mainly used outside the household generates 185 price observations fewer than an item which is used indoor. As before, the two effects reinforce each other: a PRA that sells an Apple product for outdoor use generates 204 fewer observations. The estimates of the complete model (see column 6) show that the coefficient for the interaction term $(-151)$ remains the only statistically significant one. Once again, this suggests that it is not the product brand per se that influences participants' attitudes. The brand only matters when it confers status, i.e., only when the item can be easily observed by others, as is the case for outdoor products.

\section{Conclusions}

We empirically investigate a peculiar online selling mechanism, the so-called price reveal auction, and show how the social attributes of the item on sale, partic- 
ularly the interaction of the item's brand and level of visibility, substantially affect participants' attitudes and willingness to pay.

\section{References}

[1] Augenblick, N., 2016, 'The Sunk-Cost Fallacy in Penny Auctions', The Quarterly Journal of Economics, 83, 58-86.

[2] Eichberger, J. and Vinogradov, D., 2015, Lowest-Unmatched Price Auctions, International Journal of Industrial Organization, 43, 1-17.

[3] Gallice, A., 2009, 'Unique Bid Auctions with Signals', Carlo Alberto Notebooks 112 .

[4] Gallice, A., 2016, 'Price Reveal Auctions', The B.E. Journal of Theoretical Economics, 16, 485-514.

[5] Hinnosaar, T., 2016, 'Penny Auctions', International Journal of Industrial Organization, 48, 59-87.

[6] Johansson-Stenman, O., and Martinsson, P., 2006, 'Honestly, why are you driving a BMW?', Journal of Economic Behavior \& Organization, 60, 129-146.

[7] Krishna, V., 2002, Auction theory, San Diego: Academic Press.

[8] Rege, M., 2008, 'Why do people care about social status', Journal of Economic Behavior \& Organization, 66, 233-242.

[9] Shane, F., 2012, 'Overestimating others' willingness to pay', Journal of Consumer Research, 39, pp. 1-21.

[10] Van de Ven, N., Zeelenberg, M. and Pieters, R., 2011, 'The envy premium in product evaluation', Journal of Consumer Research, 37, 984-998. 